\title{
تحوّل الطريقة التيجانية في المعاهل الحليثة عند رأي بيتز البيرغر TAHAWWUL ATH-THARIQAH AT-TIJANIYYAH FI AL-MAAHID AL-HADITSAH INDA RA'YI BITER ALBAGHIR
}

Iwan Kuswandi, ${ }^{1}$ Tobroni, ${ }^{2}$ Aאhsanu[ In'am, ${ }^{2}$ Khozin, ${ }^{2}$ Ach. Nurholis Majid ${ }^{3}$ ${ }^{1} \mathrm{PhD}$ Student in Islamic Education University of Muhammadiyah Malang

${ }^{2}$ University of Muhammadiyah Malang

${ }^{3}$ Institut Dirosat Islamiyah Al-Amien Prenduan Sumenep

Email: iwankus@stkippgrisumenep.ac.id

ركز الباحث إلى أن يبحث شأن الطريقة التيجانية من شكل التخارج الذي قام به الشيخ

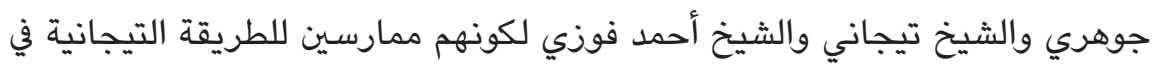
معهد الأمين الإسلامي برندوان، وجميعهم قادة المعهد ورؤساء الأمور في فتراتهم الخاصة لـاصة.

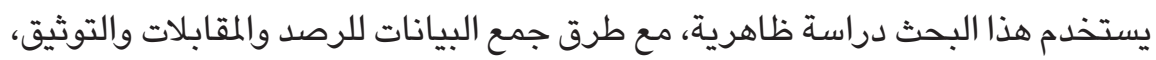

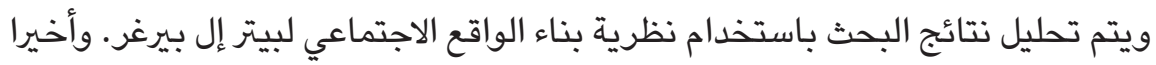

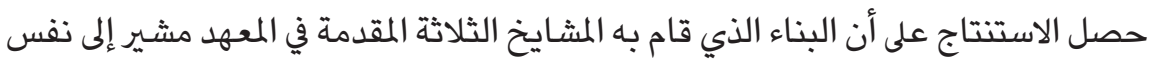

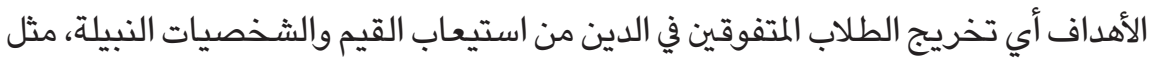

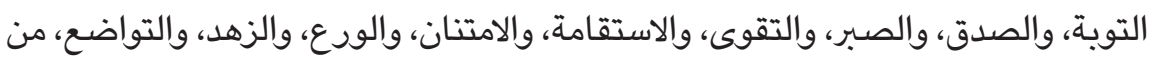

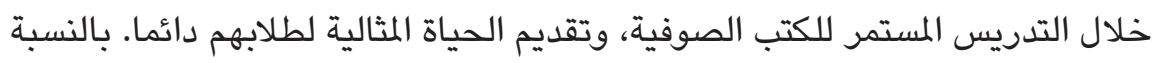

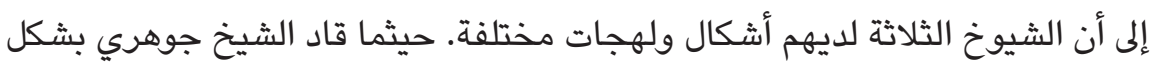
فردي، بينما من فترة الشيخ تيجاني إلى الشيخ أحمد فوزي تم تشكيل مجلس الريخ الرياسة، 
والذي نفذ الإدارة الحديثة والقيادة الجماعية. أشرك الشيخ جوهري الطلاب في الطريقة التيجانية، باختلاف ما لم يحث عليه الاثنان الآخران الطلاب على اتباع الطريقة التيجانية.

\section{Abstract}

This study constructs the form of externalization performed by Kiai Djauhari, Kiai Tidjani, and Kiai Ahmad Fauzi as practitioners of the Tijaniyah Order at the Al-Amien Prenduan Islamic Boarding School, all of which are leaders and caregivers based on their respective periods. Moreover, while this is phenomenological-based research, its data collection methods appear to consist of observation, interviews, and documentation. Furthermore, the research findings are analyzed through the theory of Social Reality Construction of Peter $L$ Berger. In accordance with the conclusion, it revealed that the construction carried out by the three Kiais at the Islamic Boarding School possesses the same meaning, namely to produce mutafaqquh fiddin students by internalizing noble values and characters such as repentance, honesty, patience, god-fearing piety (taqwa), steadfastness (istiqamah), gratitude, abstinence (wara'), asceticism (zuhud'), sincerity and humility by continuously teaching the books of Sufism as well as providing an exemplary life for their students. However, the three of them have different forms and accentuations. While Kiai Djauhari seemed to lead individually, either Kiai Tidjani or Kiai Ahmad Fauzi appeared to lead by forming a Riasah Council which implemented modern management and collegial leadership in their respective periods. In addition, while Kiai Djauhari involved students in practicing the Tijaniyah Order, it seemed that the other .two did not encourage students to do so

Keywords: Tijaniyah Order; and Modern Islamic Boarding School.

المقدمة

قد بدأ تاريخ تطور الطريقة التيجانية والتي بدأ أحدها في قرية برندوان سومنب

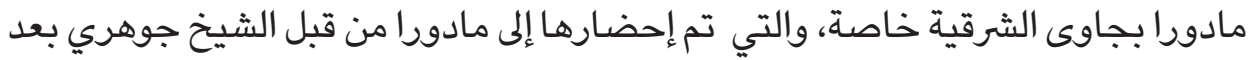

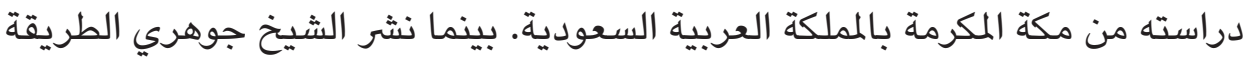
التيجانية بادئ ذي بدء في قرية برندوان إذ لم يقاومها عدد قليل من الناس والزعماء الدينيين فيها. وتلك ما يمكن أيضا العثور على تناقضات مماثلة وتجريتها من قبل بلد ممارسي

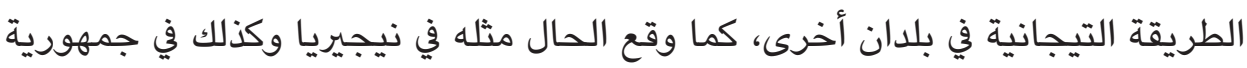

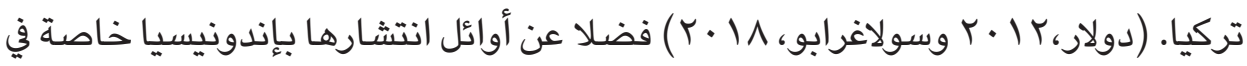

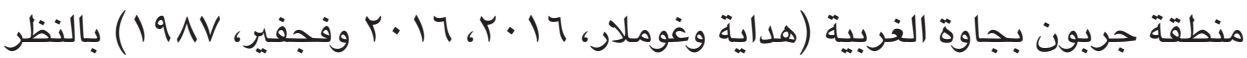

el Harakah Jurnal Budaya Islam Vol. 23 No. 2, 2021 
إلى السبب بدأ الشيخ جوهري في انتشار الطريقة التيجانية من خلال عائلته وأتاربه، ثم

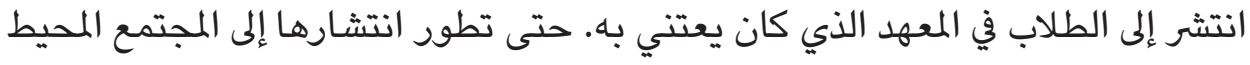

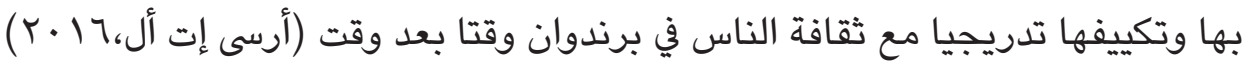

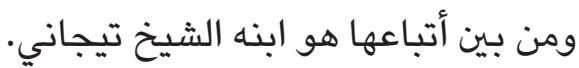

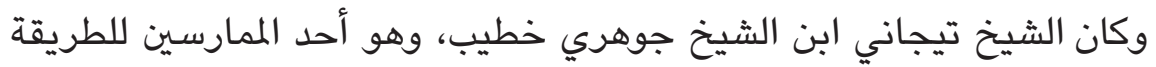

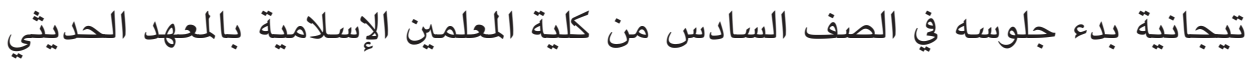

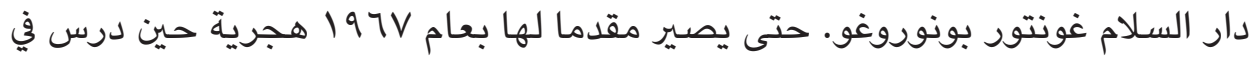

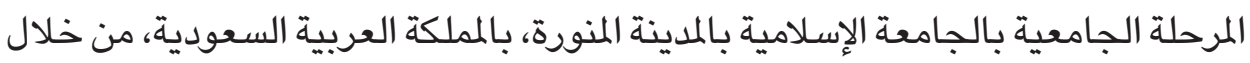

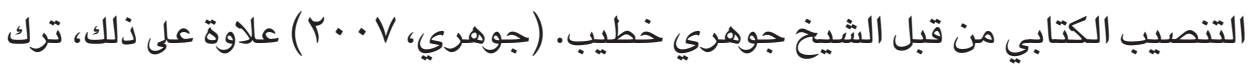

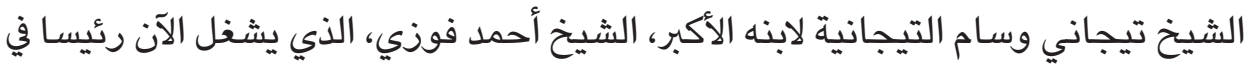
منصب الرئيس بمعهد الأمين الإسلامي برندوان. والتزمت فترة الشيخ التيجاني وفترة الشيخ أحمد فوزي الإندي عن معهد الأمين الإسلامي

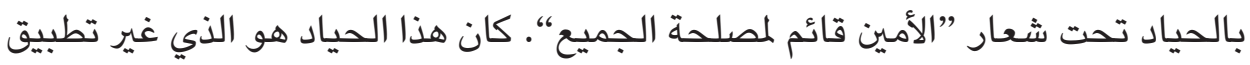

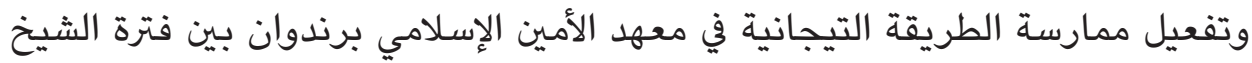

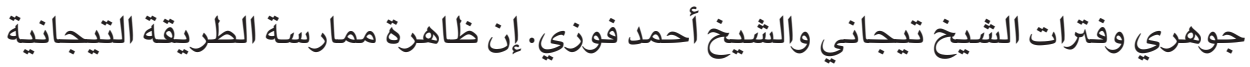
التي حدثت في معهد الأمين الإسلامي مثيرة للاهتمام إذا تم دراستها من إحدى نظي نظريات إن بيتر

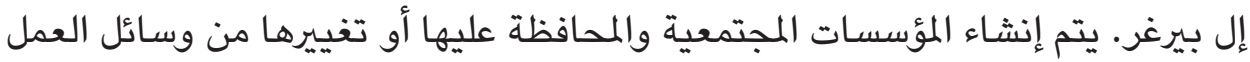

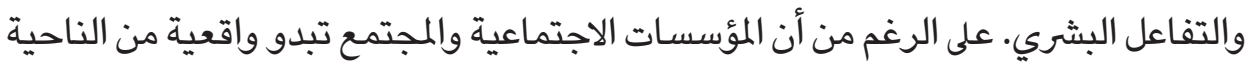
الموضوعية، إلا أنها في الواقع مبنية على تعريفات ذاتية من وسيطة العملية التفاعلية. يمكن

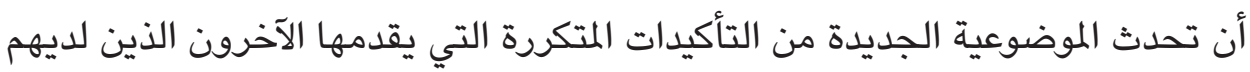

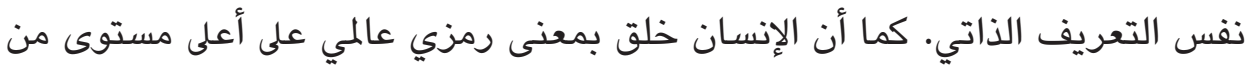

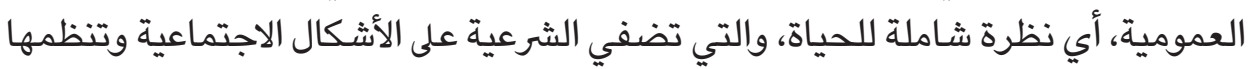

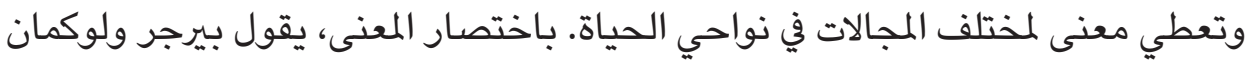

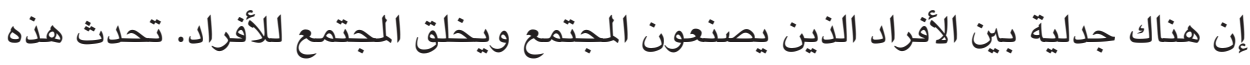

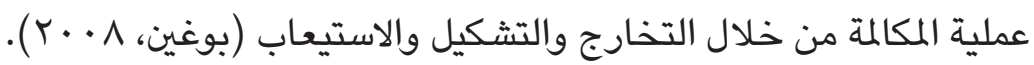

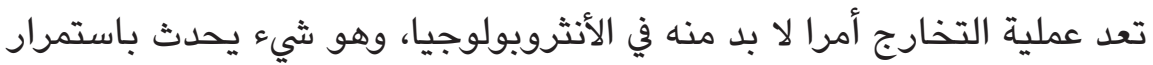

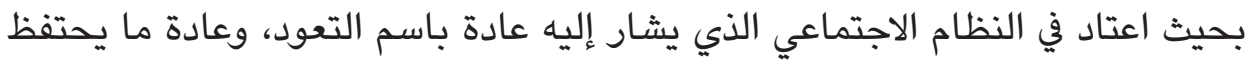

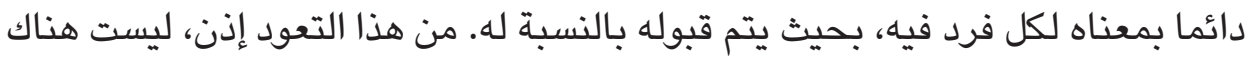




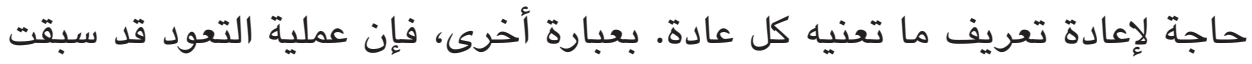

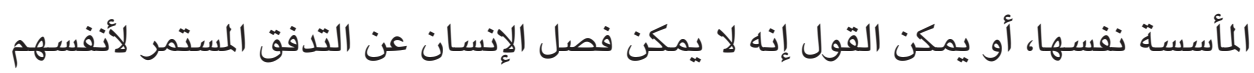

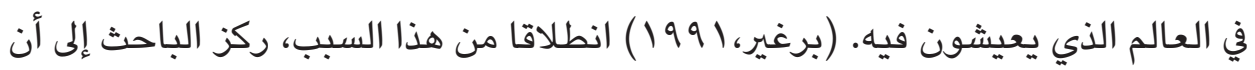

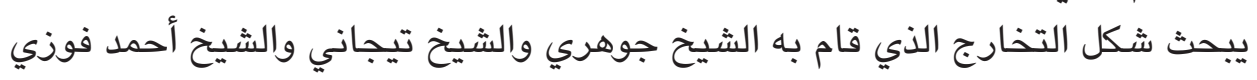
كممارسين للطريقة التيجانية في المؤسسة التعليمية بمعهد الأمين الإسلامي بقيادي التيادة المشايخ الثلاثة في فترات كل منهم.

البيانات

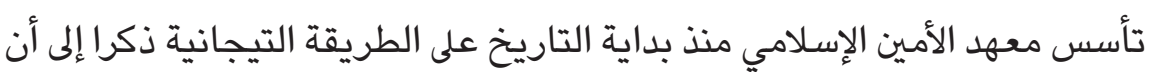
المؤسس الشيخ جوهري الذي يمارس الطريقة التيجانية. حيثما بدأ من قيادته جميع الأمور

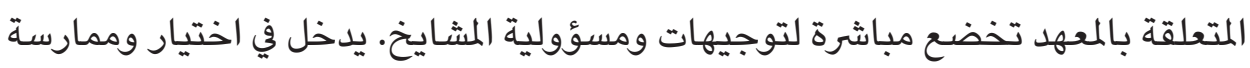

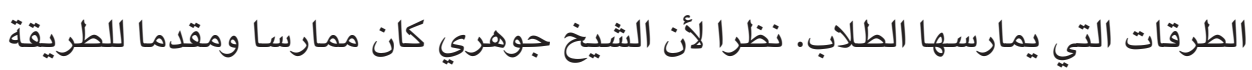

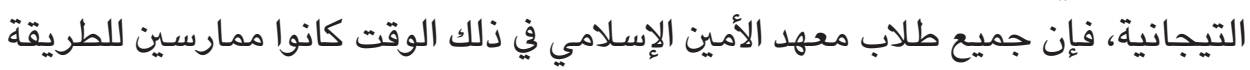

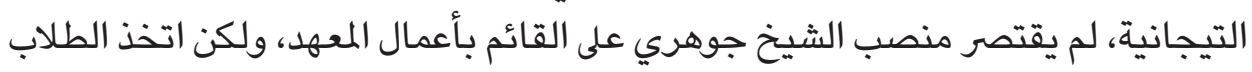
منصب الشيخ جوهري كمعلم روحي لأنه كان زعيم الطريقة التيجانية.

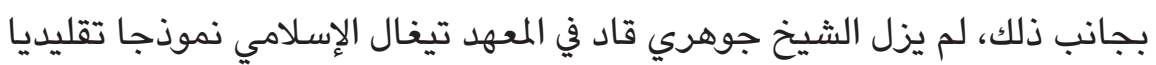

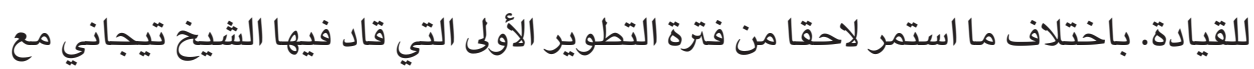

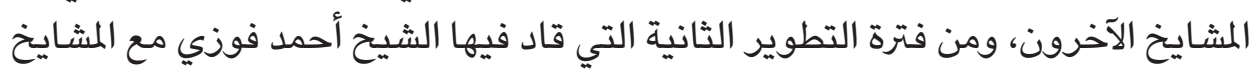

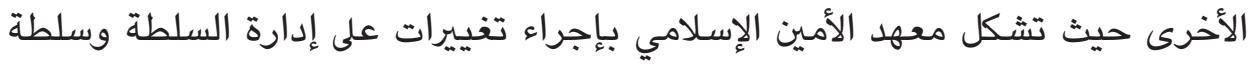

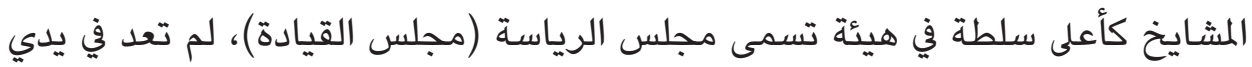

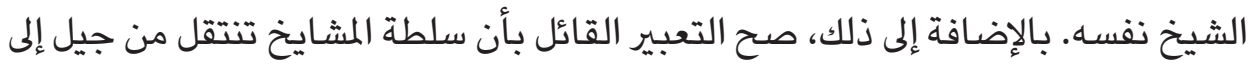
جيل، بحيث تعتبر منطقة مجتمع المعهد (مملكة صغيرة) (ظافر، 1910 (19). بمعنى لا يتم توريث المشايخ فحسب، بل يمكن إنشاؤه من خلال العملية التعليمية الصحيحة مجية أيضا.

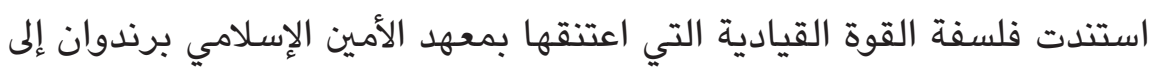

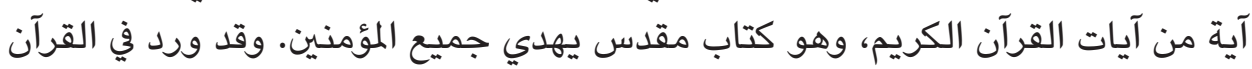

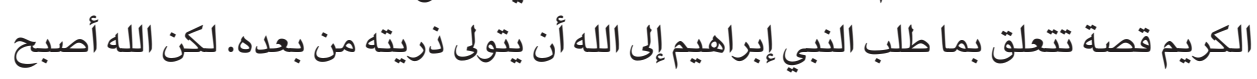

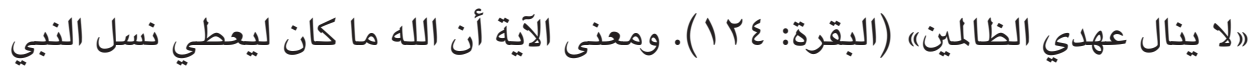

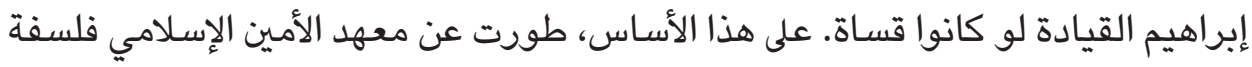


مفادها أن القادة غير مولود بل يتولد من خلال نظام التعليم. بالطبع بدأ هذا التغيير من

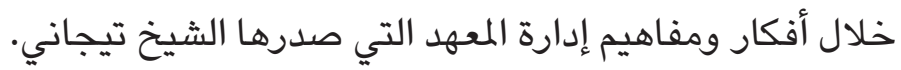

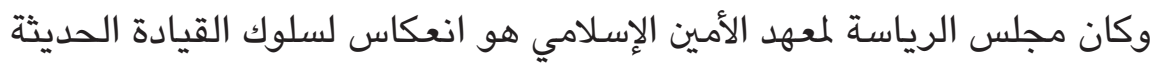

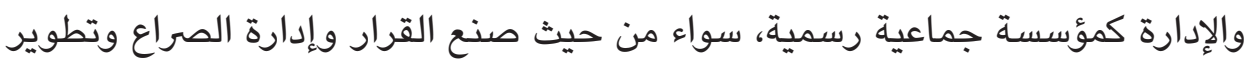

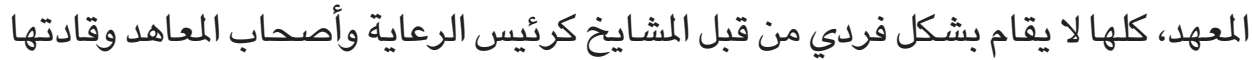

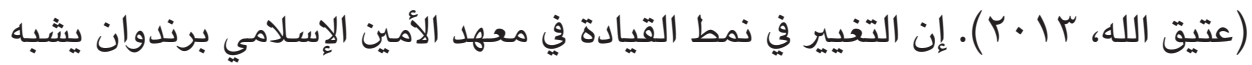

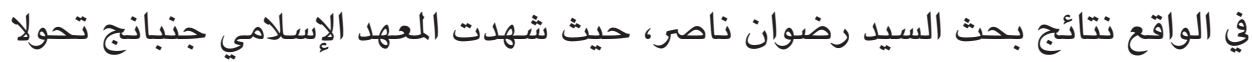

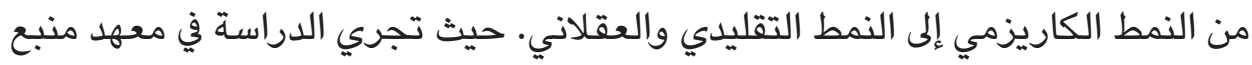

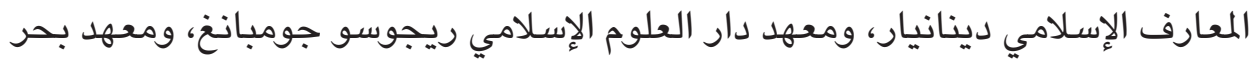

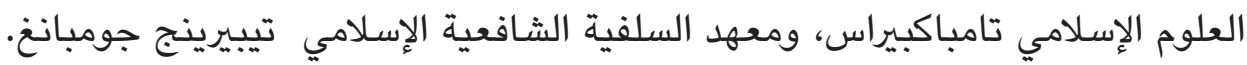

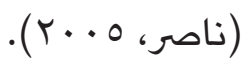

إضافة إلى ذلك، فإن التغييرات الأخرى بين فترة إنشـاء الشيخ جوهري وفترتي التطوير

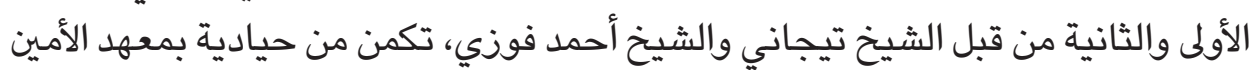

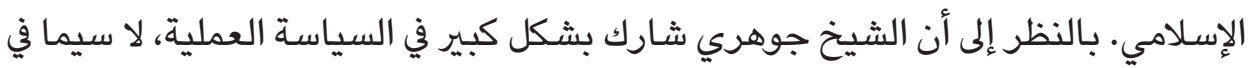

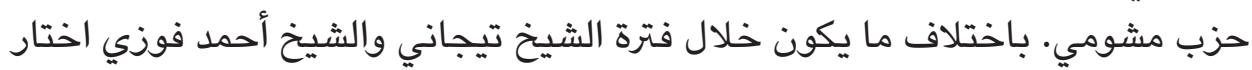

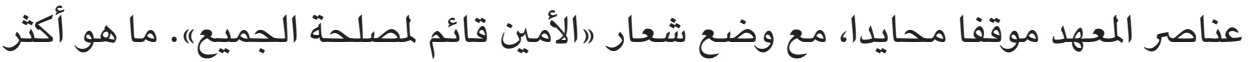
إثارة للاهتمام هو أن هذا الشعار له تأثير أيضا على ممار مارسة المارين فائل الطريقة التيجانية التي

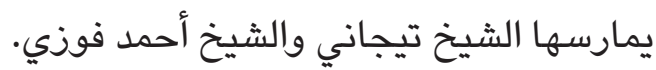
فضل الشيخ جوهري في نشر الطريقة التيجانية الدعوات الشفوية لطلابه بكونه

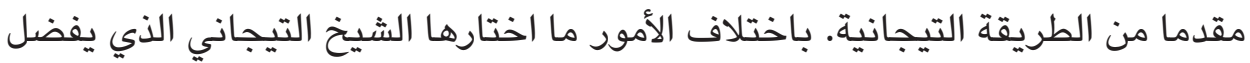

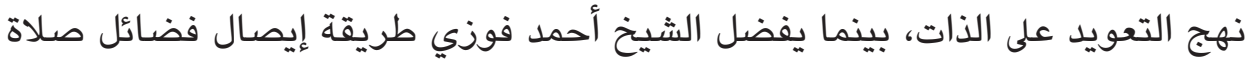

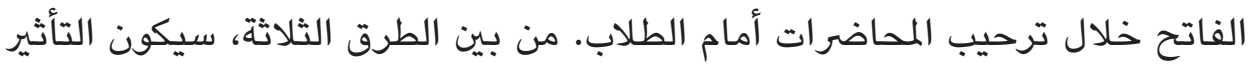

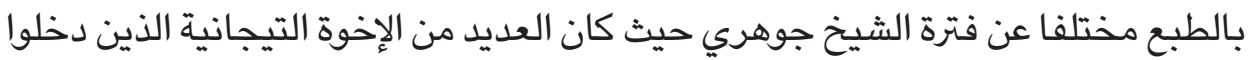

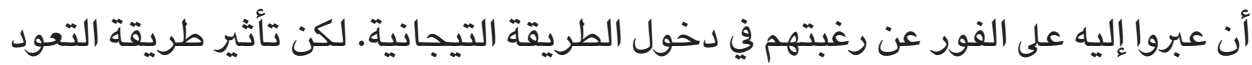

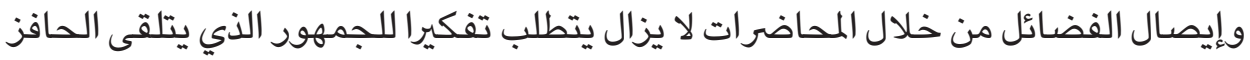

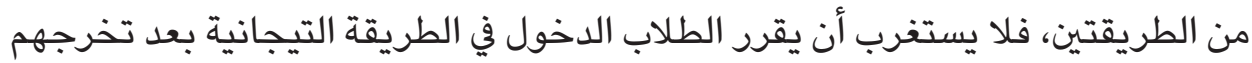
من معهد الأمين الإسلامي برندوان. 


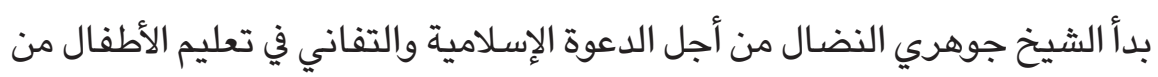

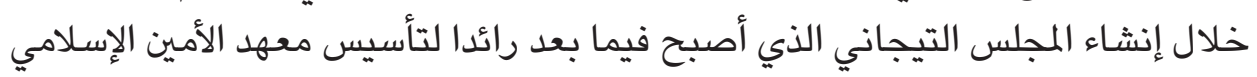

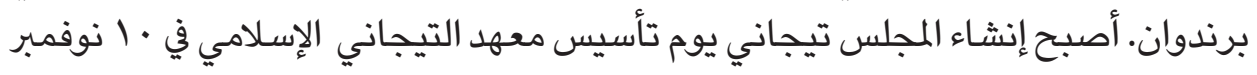

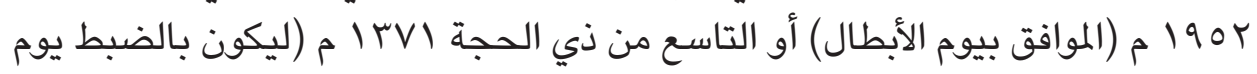

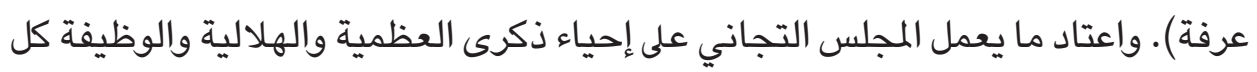

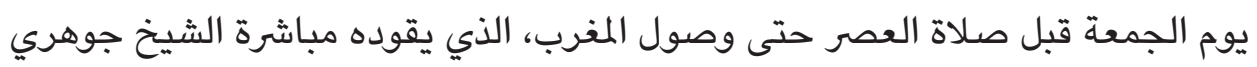

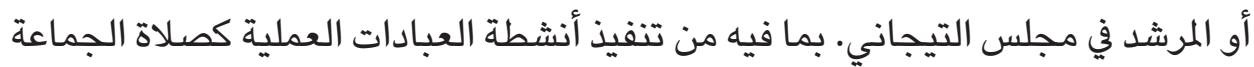
خاصة. في الواقع، ليس من النادر أن يعمل المجلس التجاني أيضا كمكان لأنشطة التعلم

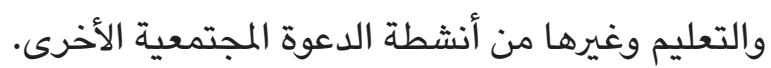

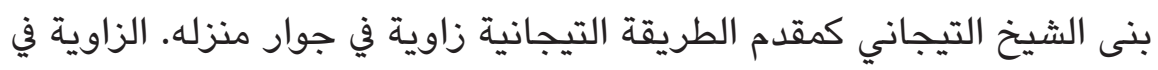
عهد الأسرة العباسية هي المكان الذي يستخدم عادة لتدريس الطريقة الذي يقع في زاوية

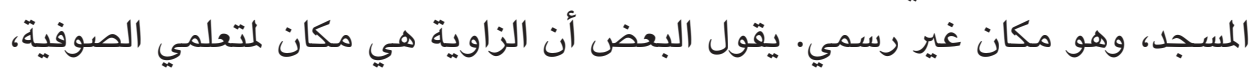

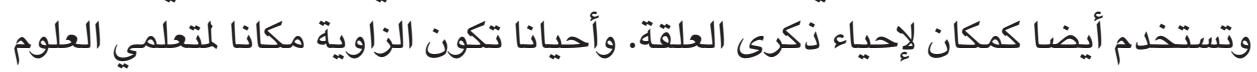

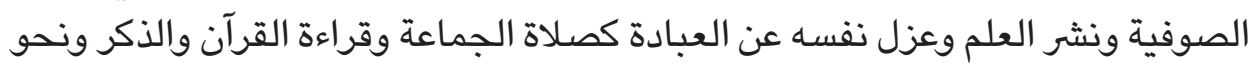

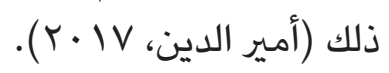

وليست الزاوية في منزل الشيخ تيجاني كنشاط للطريقة التيجانية التي استعملها

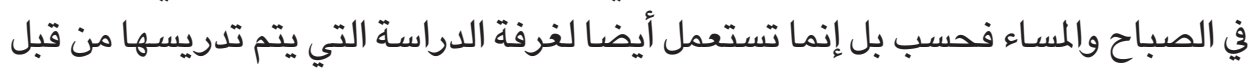

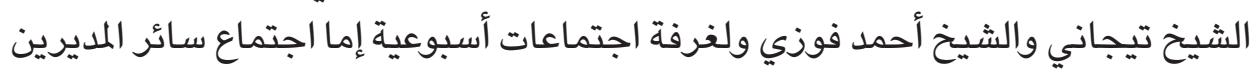
لمؤسسة الأمين المنعقد صباح كل ثلاثاء أو الاجتماع الأسبوعي لمديري معهد تحفيظ احتئ القرآن بمعهد الأمين الإسلامي برندوان. من الأهمية بمكان، بجانب جعل الشيخ تيجاني الزاوية في منزله، بدأ أيضا في بناء مسجد الجامع الأمين برندوان أينما يعد المسجد مكانا يصلي فيه الطلاب جمان جماعة فإنها لإنه

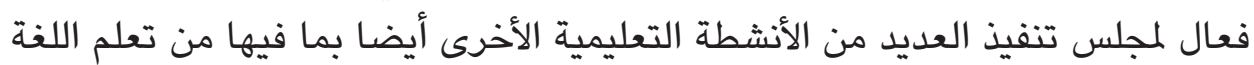

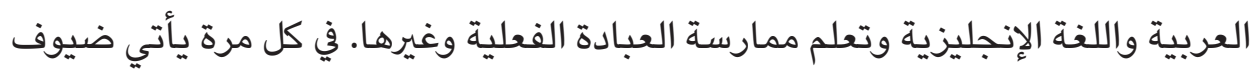
من علماء الطريقة التيجانية مثل المغرب للبقاء على اتصال مع عوامل المعاهد الإسلامية

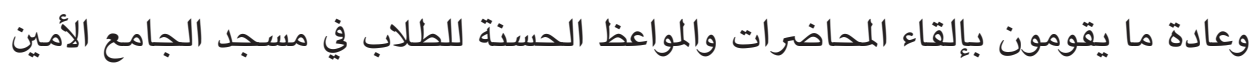
برندوان. حتى يصير وجود المسجد حقا مركزا للدعوة والأنشطة التعليمية بمعهد الأمين الإسلامي برندوان.

el Harakah Jurnal Budaya Islam Vol. 23 No. 2, 2021 


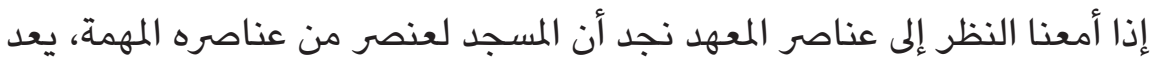

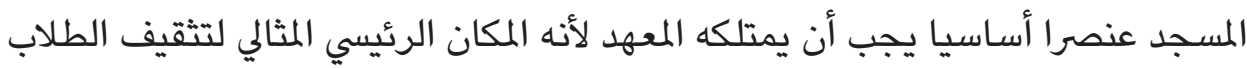

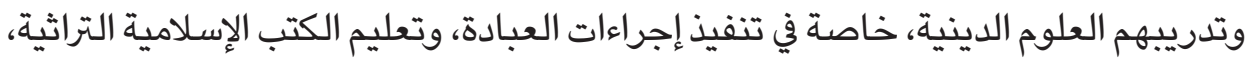

$$
\text { والأنشطة الاجتماعية (نتى إت أل، ب . . Y). }
$$

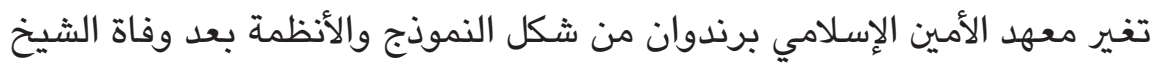

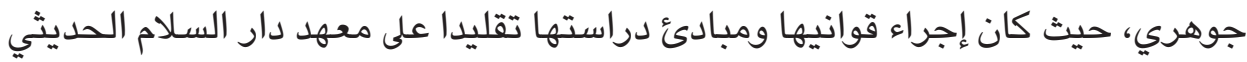

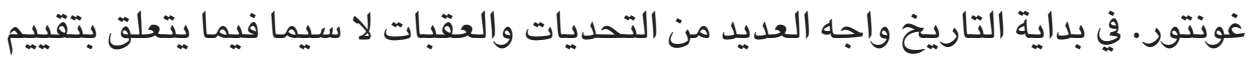
المجتمع المادوري الذي اعتبر معهد الأمين الإسلامي برندوان التهان معهد المحمدية، بينما كانت

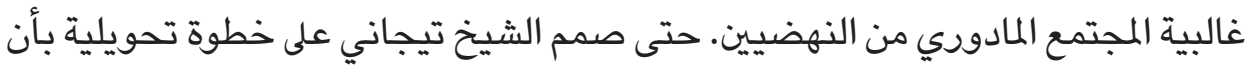

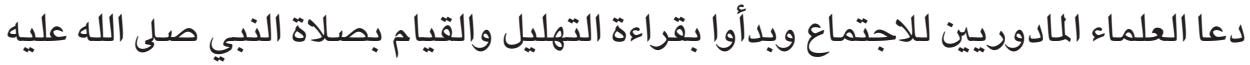
وسلم والحول أي ذكرى وفاة شخص. حتى اختفى تقييم معهد الأمين الإسلامي برندوان

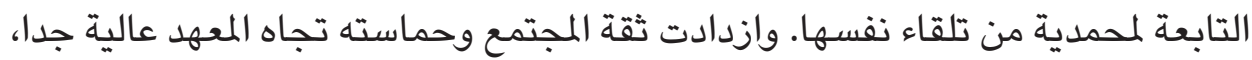

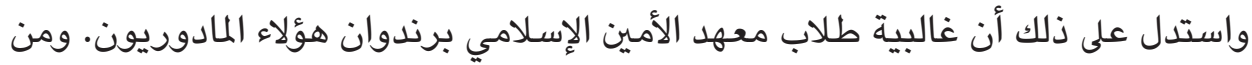
تاريخ حياة الشيخ تيجاني تم الوثوق به ليكون المنسق المركزي لهيئة اجتماع العلماء للمعاهد الإسلامية بمادورا (البصرة)، وهي منظمة تتظلل على المعاهد الإسلامية بمادورا.

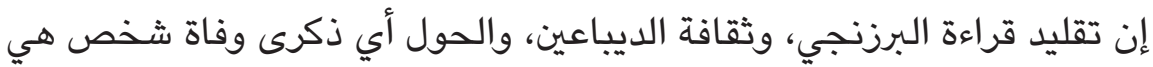

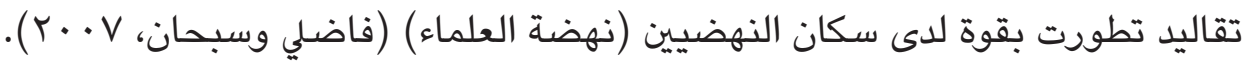

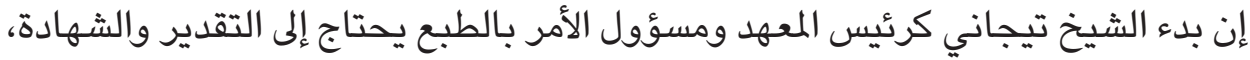
ذكرا إلى أنه أدى اختراقه بلدوة المشايخ من مادورا إلى تغيير تقييم المعاهد له يؤثئر تمامدا.

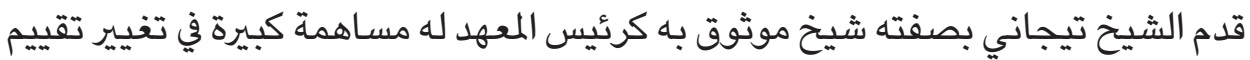

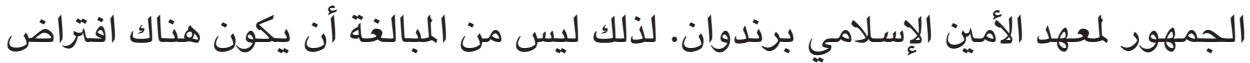
بأن الشيخ هو العنصر الرئيسي للمعاهد الإسلامية.

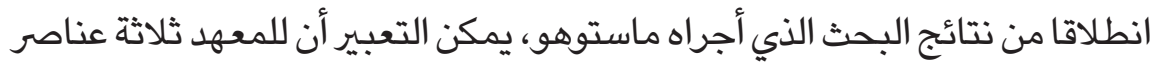
رئيسية، وهي: أولا: تتكون الجهات الفاعلة من المشايخ والأساتيذ والطلاب والمديرين. ثانيا:

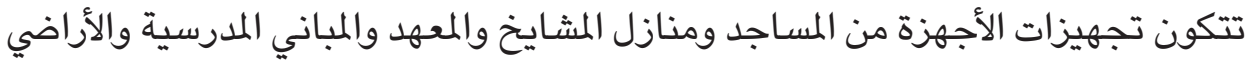

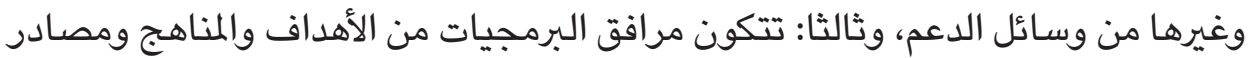
التعلم التعليم وغيرها (ماستوهو، ع ع9 19 ). 


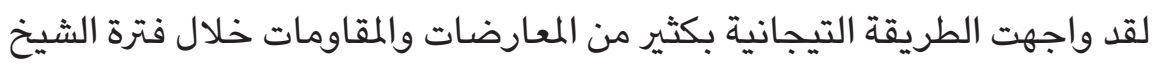

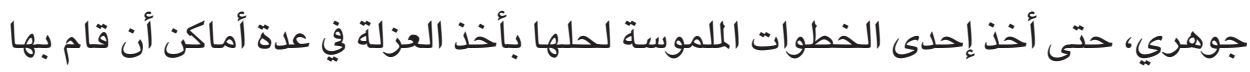

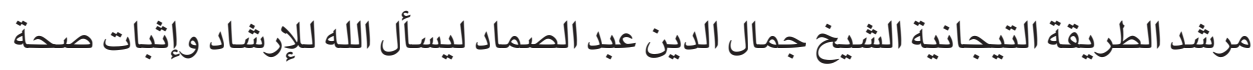

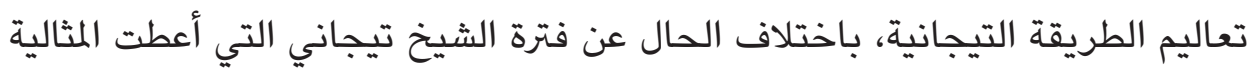

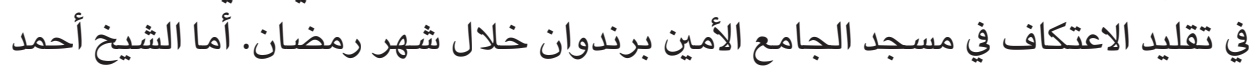

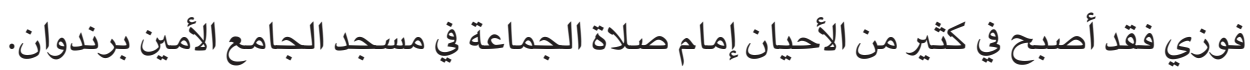

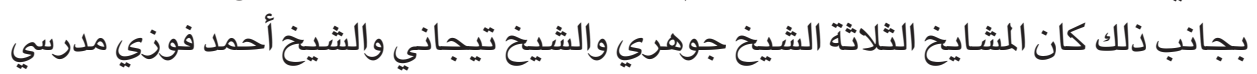
الكتب التراثية في فتراتهم الخاصة، قام الشيخ جوهري بتدريس الكتب الأخلاقية، والشيخ وانيخ

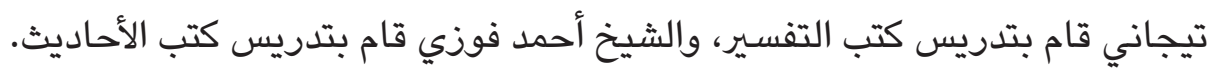

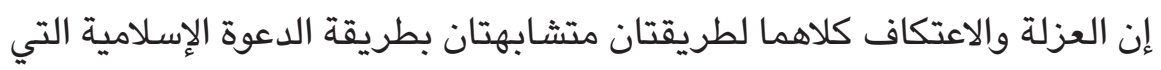

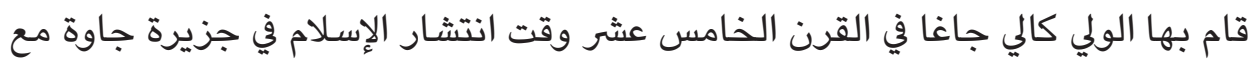

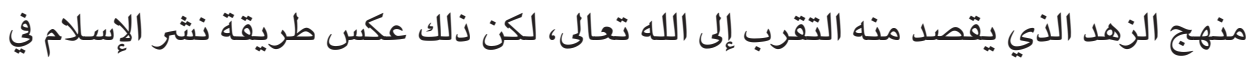

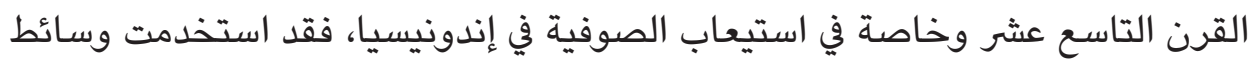

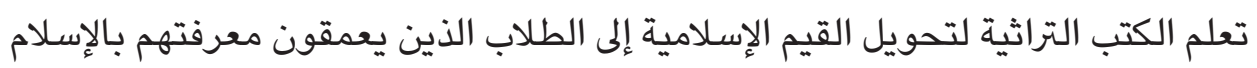

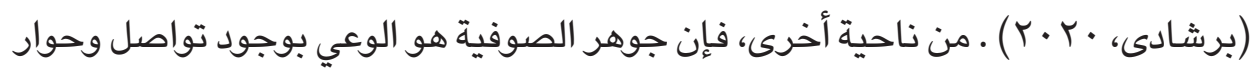

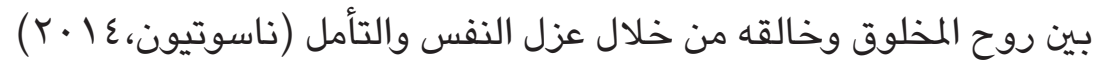

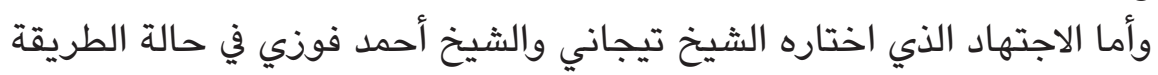

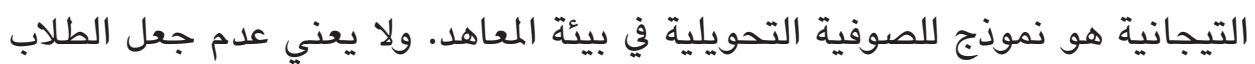

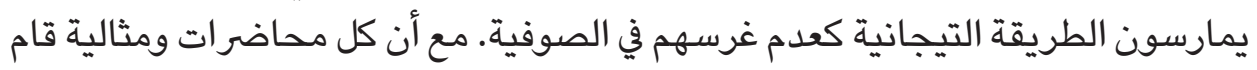

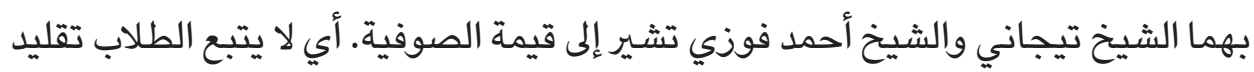

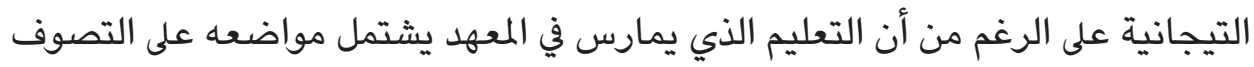

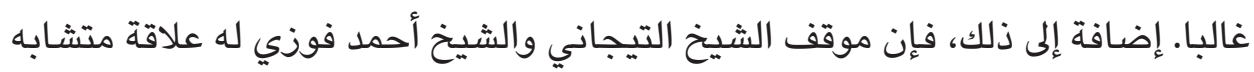
في عالم الصوفية بين الشيخ وطلابه للحصول هدف رئيسي على رضا إضيخ الله سبحانه وتعالى.

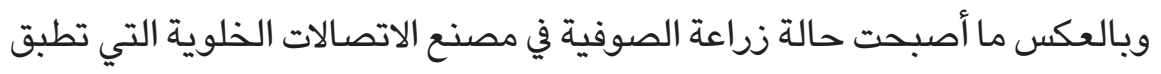
نموذجا وظيفيا وتحوليا. إن استيعاب الصوفية لا ينضم رسميا إلى مجموعة تنظيمية

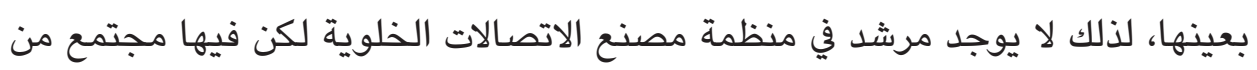

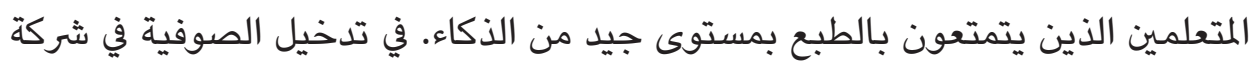

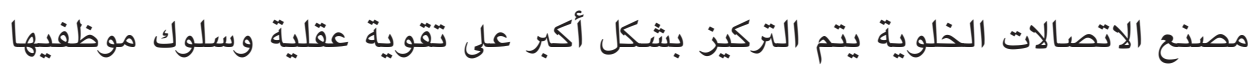


التي تتم بشكل مستقل، على عكس منظمات الطريقة التيجانية التي تتطلب مرشدين في الصوفية. كان كل ذلك مدفوعا من قبل قسم إدارة رأس المال الروحي. الأنشطة التي مني

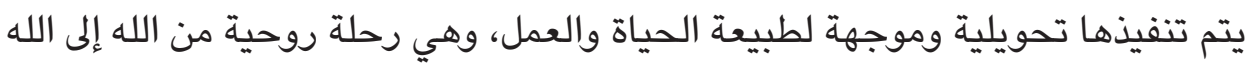

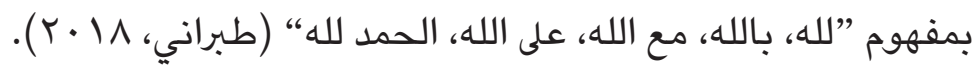
اشتركت الظاهرتان المذكورتان بعضها واختلفت قطاعات بعضها. تكاد تكون ظاهرة

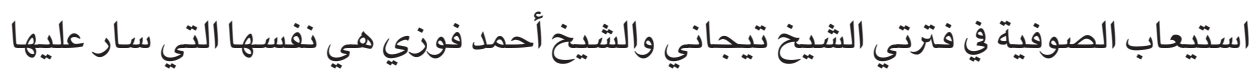

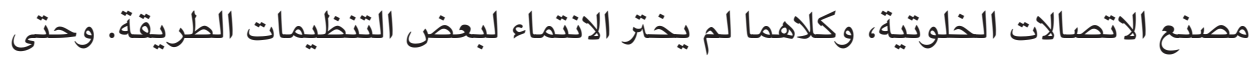

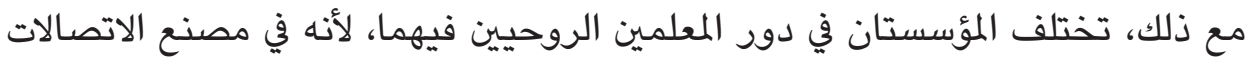

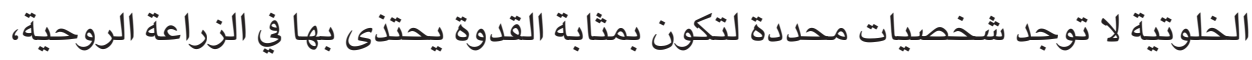
أي النظام الذي ينفذ الاستيعاب الداخلي. بخلاف عنه ما يكون في معهد الأمين الإسلامي

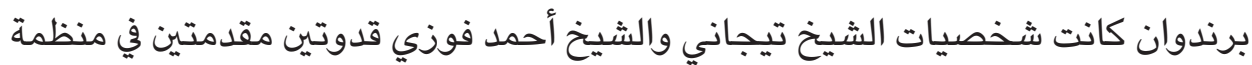
الطريقة التيجانية.

وليس وجود الطريقة التيجانية شيئا رسميا في المعاهد منذ فترة قيادة الشيخ

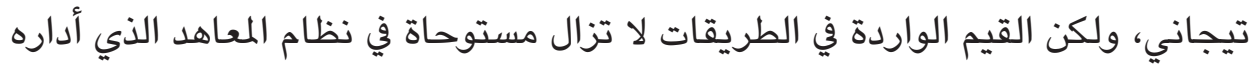

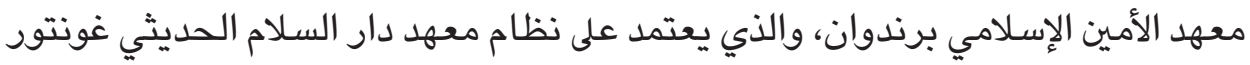

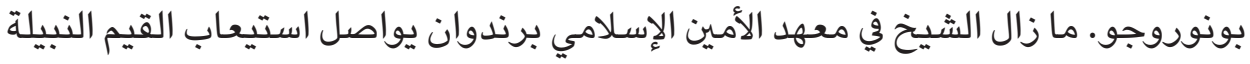

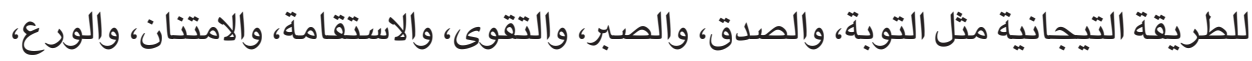

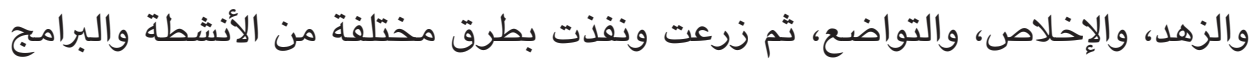
بمعهد الأمين الإسلامي برندوان. وكان تعليم الطلاب وتدرييهم على التثقيف يتم في مجال مكافحة الفساد قصدا لتحقيق القيم الصادقة. وكانت الممارسة العملية في هذا المجال بإدارة الطلاب وحدماب وحدات

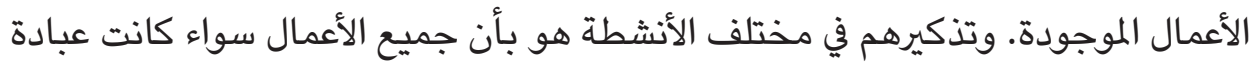

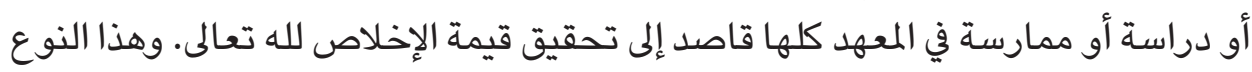
من نموذج غرس القيمة الذي يصفه عبد الرحمن وحيد بأنه ثقافة فرعية في سياق المعهد

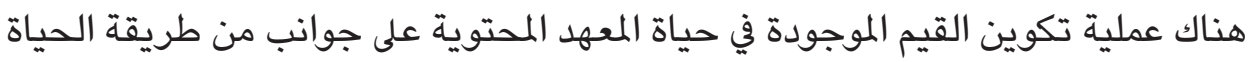

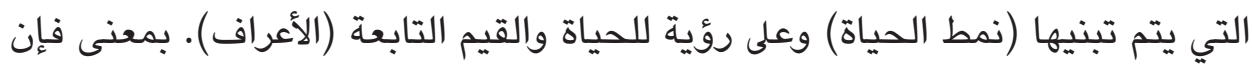
دور المشايخ في المعاهد يعتبر حاسما في التعامل مع التغيير والتحويل، لأنه يتمتع بتوجه ولها صوفي يوفر الانضباط الأخلاقي ومستوى عال من التماسك (واحد، • ( • ). 
من ناحية أخرى، فإن ما حدث في معهد الأمين الإسلامي برندوان يرفض نتائج بحث

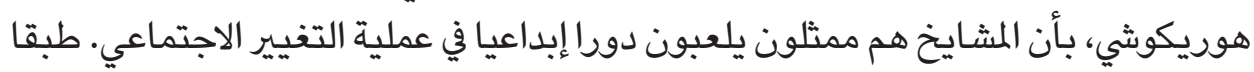

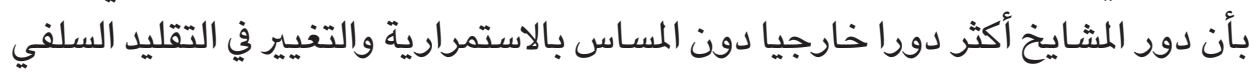

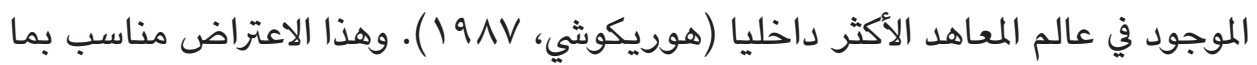

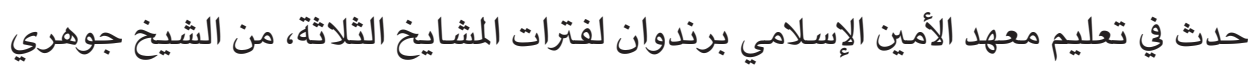

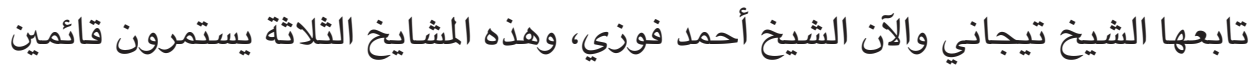

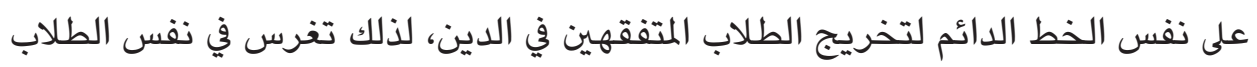

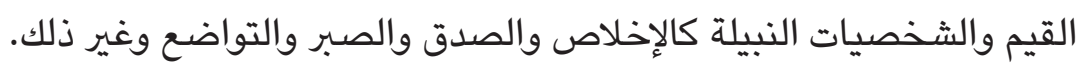
داوم المشايخ الثلاثة بتعبير طلابهم عن قيم الإخلاص شفهيا في مناسبات مختلفة.

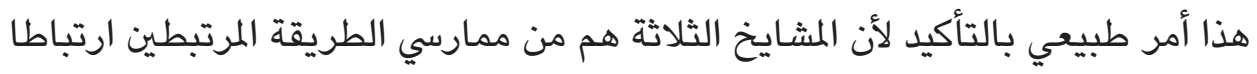

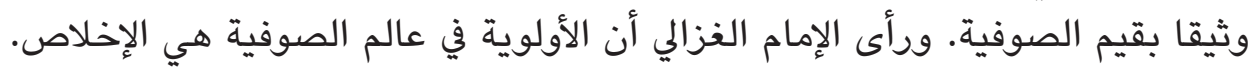

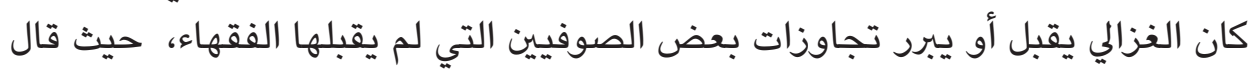

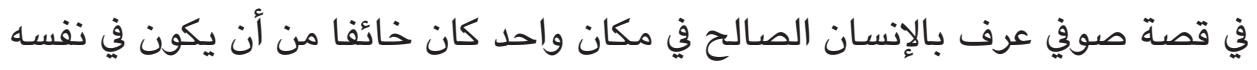

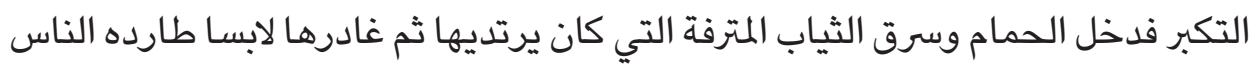

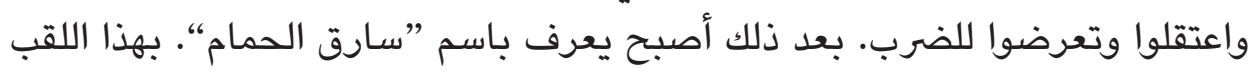

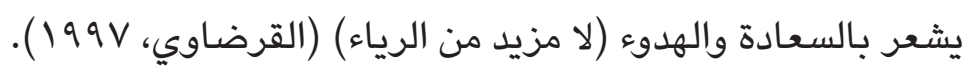

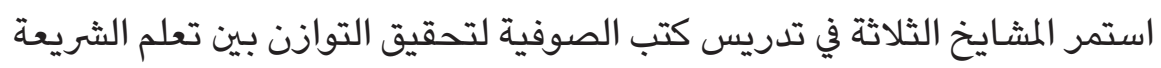

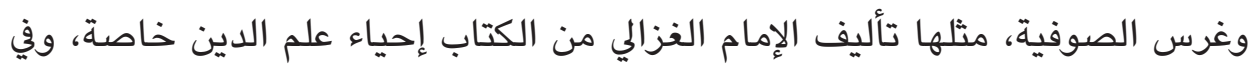

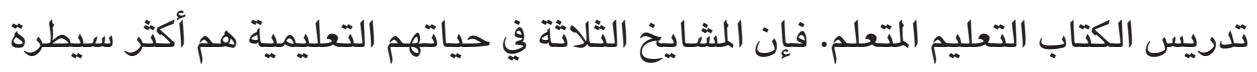

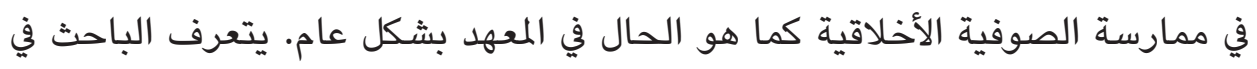

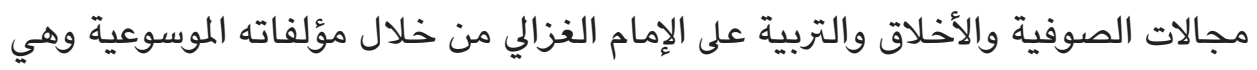

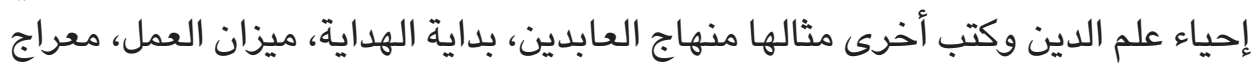

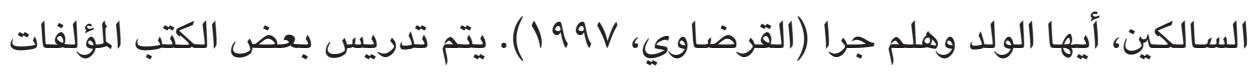

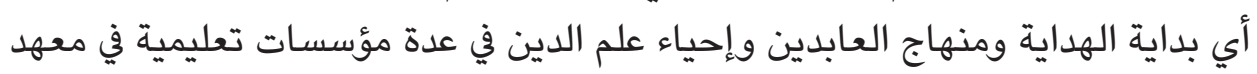

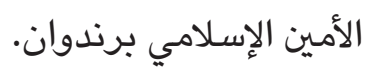
وأصبح مقدمو الطريقة التيجانية الثلاثة كانوا حازمين في الأمور الدينية حيث كان

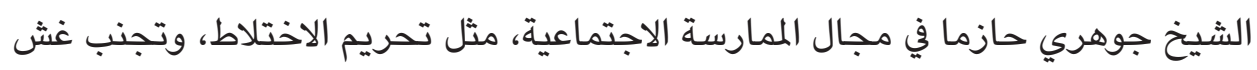
الميزان في التجارة، وذلك الحال مختلف عن الشيخ تيجاني والشيخ أحمد فوزي، وهما 
حازمان في مسائل الفكر خاصة بمناهضة الليبرالية في الإسلام. وكذلك ما يتبعه الآخر من

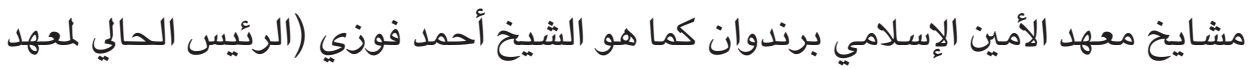
الأمين الإسلامي برندوان). وكانت الشخصيات الثلاثة الشيخ جوهري والشيخ تيجاني والشيخ أحمد فوزي

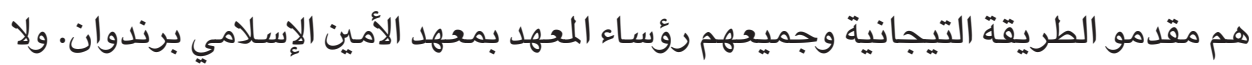
يمكن إنكاره أن التنشئة الاجتماعية تحدث دائما في سياق بنية اجتماعية معينة، لا يكفي

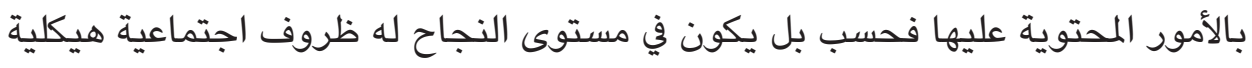

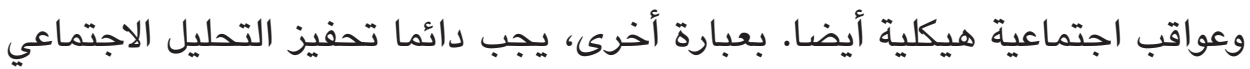
الدقيق أو التحليل الاجتماعي النفسي لظواهر الاستيعاب من خلال فهم اجتماعي كلي لئي

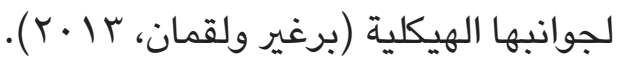
وعلى إثر ذلك، فإن مقياس النجاح الذي قام به الشيخ جوهري نجان نه في التنشئة الاجتماعية لأمر الطريقة التيجانية بين الناس في برندوان هوان هو بما تدعمه قدرته كرئيس لمعهد

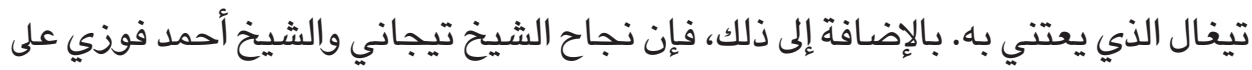

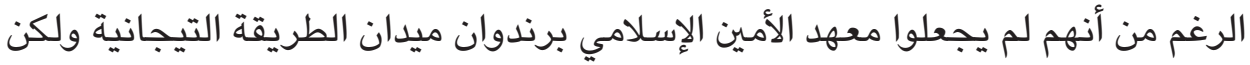

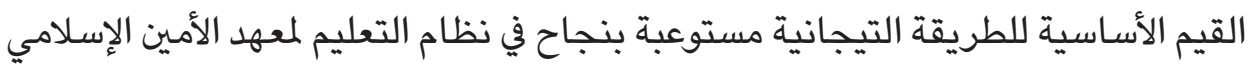
برندوان، بحيث تصبح نقطة جذب لممارسي الطريقة التيجانية في مناطق مختلفة لإرسال

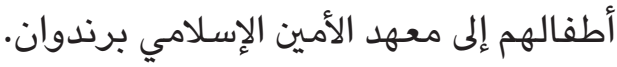
تعتبر الهوية في حد ذاتها هي عنصر أساسي للواقع الذاتي كما هي مرتبطة بالمجتمح.

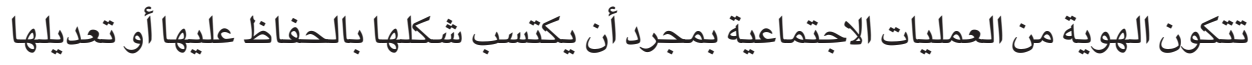

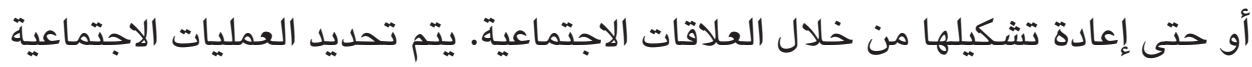

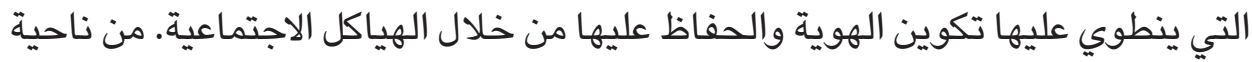

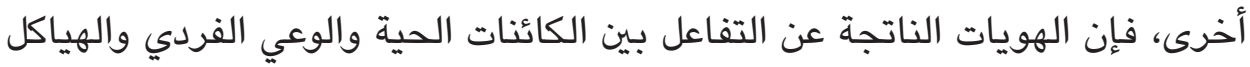

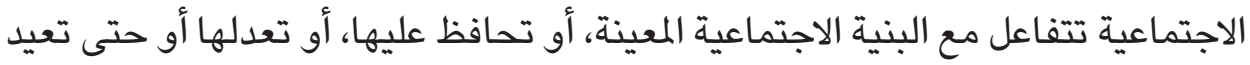

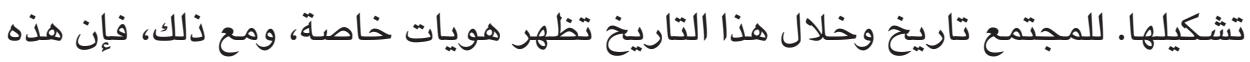

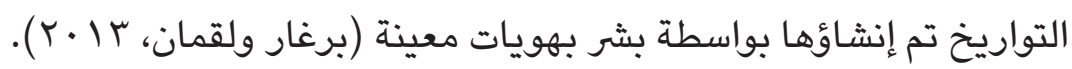

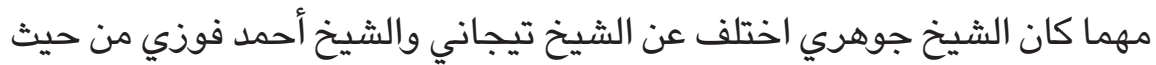

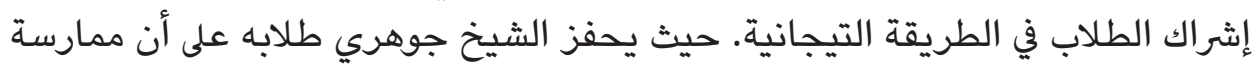
الطريقة التيجانية هي زائد لمواجهة الموت. وهو يختلف عن موقف الشيخ تيجاني والشيخ 
أحمد فوزي كممارسي الطريقة التيجانية لم يحفزا الطلاب على ممارسة الطريقة التيجانية خوفا عليهم لن يستقيموا في تنفيذ التزاماتهم في الطريقة التيجانية حتى يؤدي إنى إلى ما لا لا

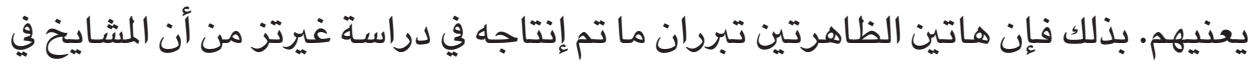

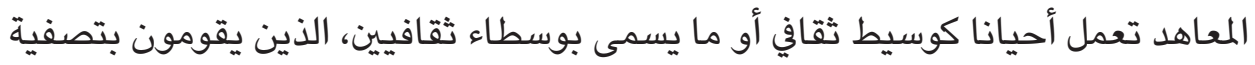

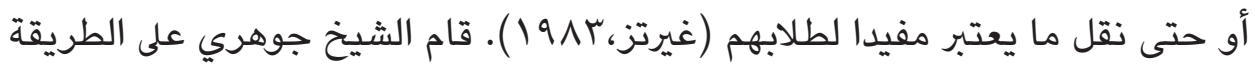

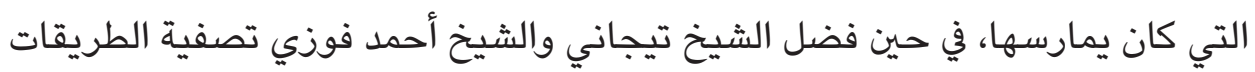

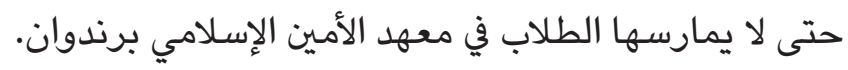

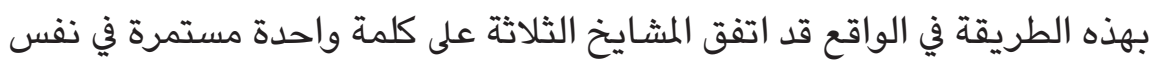

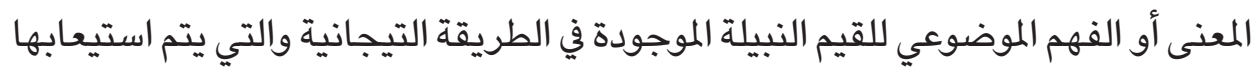
بعد ذلك في التعليم بمعهد الأمين الإسلامي برندوان. واستمرارية المعنى المذكور مكشوفة المئية

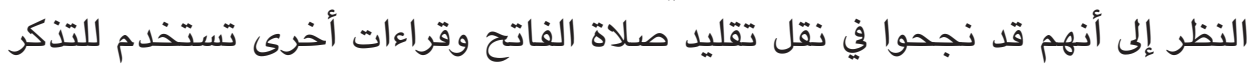

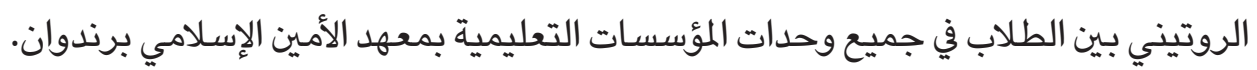

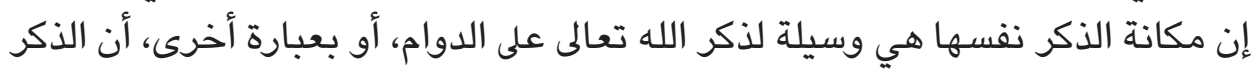

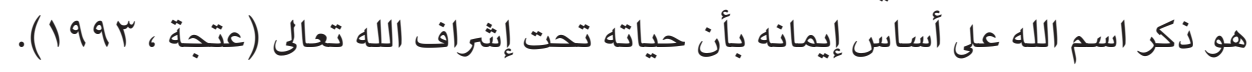

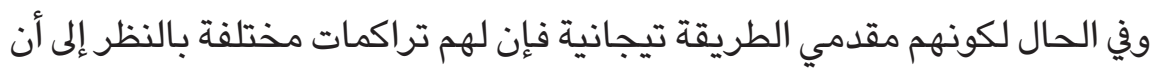

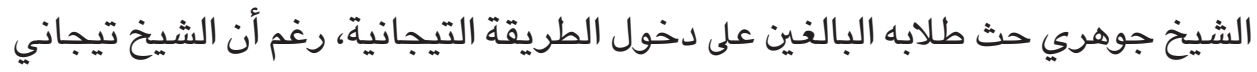

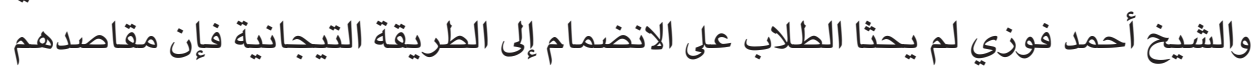
في نفس المعنى، وهو تخريج الطلاب المتفوقين في الدين من غرس القيم الفيم النبيلة الموجودة في الطريقة التيجانية.

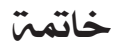

وحصل أخيرا على الاستنتاج بعد المناقشة أن بناء نموذج التخارج الذي تم تنفيذه من قبل الشيخ جوهري والشيخ تيجاني والشيخ أحمد فوزي كممارسين للطريقة التيجانية في

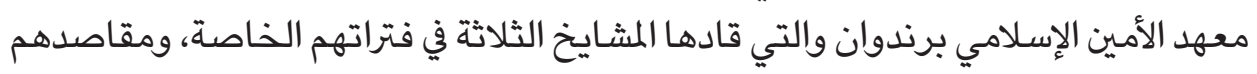

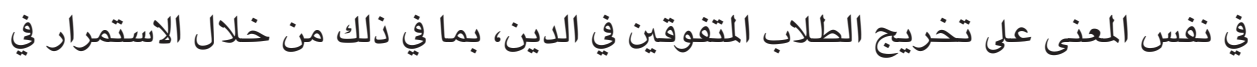

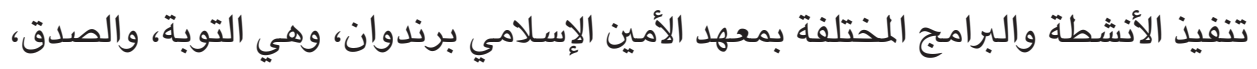

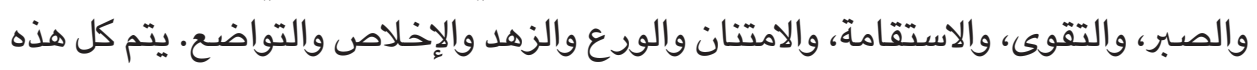

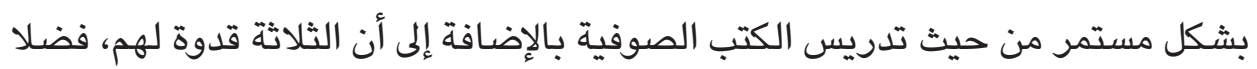

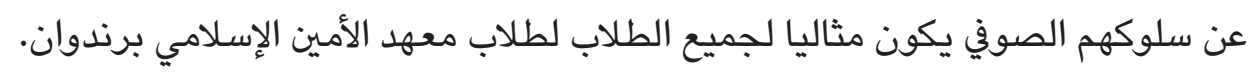


ويجانب ذلك، فإن المشايخ الثلاثة اختلفت خطواتهم من حيث شكلها ولهجاتها.

قام الشيخ جوهري بيناء مجلس التجاني في منطقة معهد تيغال الإسلامي، وتمثل عهده

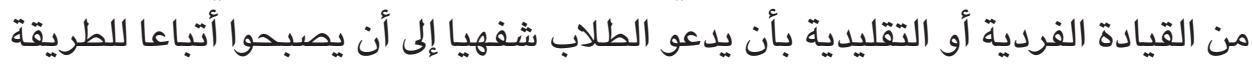

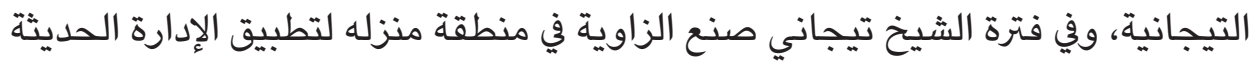

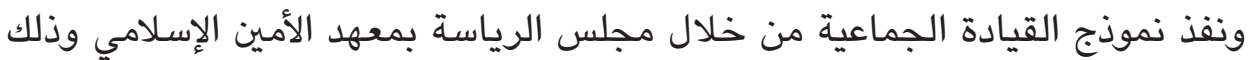

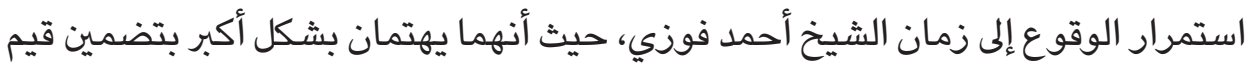

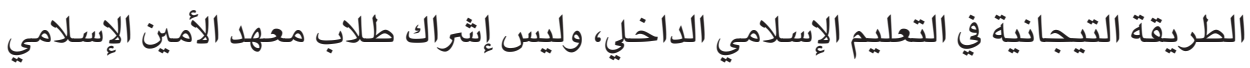
رسميا للدخول إلى الطريقة التيجانية.

\section{المراجع}

Amirudin, M. F. (2017). Lembaga Pendidikan Kaum Sufi Zawiyah, Ribath dan Khanqah. El-Ghiroh, 12(1), 119-132. https://doi.org/https://doi. org/10.37092/el-ghiroh.v12i1.30

Arsa, M. H., Munif, M., Kuswandi, I., \& Madjid, N. (2016). KH. A. Djauhari Chotib Muqaddam Tarekat Tijaniyah Madura. Mutiapress.

Atiqullah. (2013). Perilaku kepemimpinan kolektif pesantren. Pustaka Radja. Atjeh, A. (1993). Tarekat dalam tasawuf (Edisi Ke 6). Pustaka Aman Press.

Berger, P. L. (1991). Langit suci: agama sebagai realitas sosial. LP3ES.

Berger, P. L., \& Luckmann, T. (2013). Tafsir sosial atas kenyataan risalah tentang sosiologi pengetahuan. LP3ES.

Birsyada, M. I. (2020). Sufism Ethics in Javanese Aristocracy: A Historical Perspective. International Journal of Innovation, Creativity and Change, 11(10), 267-286. www.ijicc.net

Bungin, B. (2008). Konstruksi sosial media massa:kekuatan pengaruh media massa,iklan televisi dan keputusan konsumen serta kritik terhadap peter L. Berger dan Thomas Luckmann. Kencana.

Dhofier, Z. (1985). Tradisi pesantren: studi tentang pandangan hidup kyai (ke-4). LP3ES.

Djauhari, M. T. (2007). Mengenal lebih dalam thariqah Tijaniyah di Indonesia dan hierarki kepemimpinannya. Halaqah Ilmiah Internal Muqaddam 
Thariqah Tijaniyah Idul Khotmi Lil Quth Bil Maktum Sayyiduna Syekh Al-Akbar Ahmad At-Tijani 214.

Dollar, C. (2012). An 'African' Tarika in Anatolia: Notes on the Tijaniyya in Early Republican Turkey. ANNUAL REVIEW OF ISLAM IN AFRICA, 11(11), 30-34.

Fadeli, S., \& Subhan, M. (2007). Antologi NU sejarah-istilah-amaliah-uswah. Khalista.

Geertz, C. (1983). Abangan, santri, priyayi dalam masyarakat Jawa. Pustaka Jaya.

Hidayat, A. A., \& Gumilar, S. (2016). Gerakan tarekat tijaniyah di Garut, Jawa Barat, Indonesia, 1935 - 1945. SOSIOHUMANIKA: Jurnal Pendidikan Sains Sosial Dan Kemanusiaan, 9(1), 31-48.

Horikoshi, H. (1987). Kyai dan perubahan sosial. P3M.

Mastuhu. (1994). Dinamika sistem pendidikan pesantren. INIS.

Nasir, R. (2005). Mencari Tipologi Format Pendidikan Ideal Pondok Pesantren di Tengah Arus Perubahan. Pustaka Pelajar.

Nasution, H. (2014). Falsafat dan mistisisme dalam Islam (cet ke-12). PT Bulan Bintang.

Nata, A., Asmuni, A., Raya, A. T., Kusaeri, A. A., Azra, A., Yatim, B., Sudradjat, D., Hasyim, H., Shiddiq, A., Matola, G., Suparta, Mukhtar, M., Mulia, M., Haroen, H., Wahid, R. A., Jamrah, S. A., Ranuwijaya, U., Ali, Y., \& Bagir, Z. A. (2003). Suplemen Ensiklopedi Islam. In Ensiklopedi Islam (cetakan ke). PT Ichtiar Baru Van Hoeve Jakarta.

Pijper, G. . (1987). Fragmenta islamica: beberapa studi mengenai sejarah Islam di Indonesia awal abad XX. Penerbit Universitas Indonesia (UI Press).

Al-Qardhawi, Y. (1997). Pro-kontra pemikiran Al-Ghazali. Risalah Gusti.

Solagrebu, A.-R. B. (2018). The Historical Development of the Tijaniyyah Sufi Order in Ilorin, Nigeria and Challenges for Survival. Journal of Muslim Minority Affairs, 38(4), 537-550. https://doi.org/https://doi.org/10. $1080 / 13602004.2018 .1543009$

el Harakah Jurnal Budaya Islam Vol. 23 No. 2, 2021 
Tobroni. (2018). Character formation of the good deeds through transformative fashionable sufism human resources development model of muslim in PT telkom Indonesia. European Journal of Training and Development Studies, 5(4), 26-44. www.eajournals.org

Wahid, A. (2010). Menggerakkan tradisi: esai-esai pesantren. LKiS. 
